\title{
Instabilidade financeira no espaço: uma abordagem monetária da dinâmica econômica regional *
}

\author{
Teófilo Henrique Pereira de Paula ** \\ Marco Crocco ${ }^{* * *}$
}

\begin{abstract}
Resumo
O trabalho tem como objetivo analisar a relação entre variáveis monetárias e a distribuição espacial das atividades produtivas em um contexto de moeda não neutra. A metodologia consiste na construção e implementação computacional de um modelo de simulação baseado em agentes (agent-based model). Propõe-se um sistema econômico artificial que conecta, por meio do mercado de crédito, os setores produtivo e financeiro, em que o primeiro é caracterizado por concorrência imperfeita (economias de escala e diferenciação assimétrica de produtos) e o segundo, por comportamentos especulativos determinados pela preferência à liquidez. Como resultado, instabilidades geradas endogenamente foram observadas nas simulações, com efeitos sobre a distribuição inter-regional das atividades produtivas. $\mathrm{O}$ modelo reproduz importantes regularidades em economia regional, entre as quais uma distribuição rank-size consistente com a Lei de Zipf. Como implicação de política econômica, os resultados sugerem a necessidade da introdução de elementos regionalmente diferenciados na política monetária.
\end{abstract}

Palavras-chave: Região; Moeda; Agentes.

\section{Abstract \\ Financial instability on space: a monetary approach of the regional economic dynamic}

This essay aims to analyses the relationship between monetary variables and the spatial distribution of productive activities in a context of non-neutrality of money. The methodology is based on construction and computational implementation of an agent based model which links the productive sector with the financial side of the economy. The productive sector is characterized by imperfect competition (economies of scale and asymmetric product differentiation) and the financial market by speculative behaviors determined by liquidity preference. Among the results, an endogenous instability is observed with impacts on the inter-regional distribution of economic activities. The model reproduces an important stylized fact in regional economics, the Zipf Law, and suggests the need of introducing differentiated regional components in monetary policy.

Keywords: Region. Money. Agents.

JEL R1, E12, C63.

* Trabalho recebido em 21 de junho de 2013 e aprovado em 15 de maio de 2014.

** Professor do Instituto Três Rios - ITR / Universidade Federal Rural do Rio de Janeiro (UFRRJ), Rio de Janeiro, RJ, Brasil. E-mail: teohpaula@gmail.com, http://lattes.cnpq.br/6185475112340528.

${ }^{* * *}$ Professor Titular do Centro de Desenvolvimento e Planejamento Regional (Cedeplar) / Universidade Federal de Minas Gerais (UFMG), Belo Horizonte, MG, Brasil. E-mail: crocco@cedeplar.ufmg.br, http://lattes.cnpq.br/1810645213176454. 


\section{Introdução}

O presente trabalho versa sobre a relação entre a moeda e o espaço. A justificativa para tal empreendimento reside na observação de que o aspecto monetário do desenvolvimento regional é pouco considerado na literatura econômica, em grande medida como uma decorrência da dicotomia clássica, segundo a qual nenhum papel especial deve ser atribuído à moeda ${ }^{1}$. Alternativamente, o estudo se apoia na hipótese da não neutralidade da moeda, inclusive no longo prazo, tal como se depreende das formulações teóricas da escola pós-keynesiana.

Ao se considerar a hipótese da não neutralidade, o problema torna-se sensivelmente mais complexo. A moeda, na condição de meio eficiente de reserva de valor, concorre com os ativos reais, influenciando as decisões de portfólio dos agentes. Ademais, na medida em que tais decisões são tomadas em um ambiente incerto (na acepção keynesiana do termo), instabilidades podem se originar a partir da própria dinâmica do sistema. Abordagens como essa têm ocupado espaço relativamente reduzido na literatura econômica, em grande medida como decorrência da dificuldade na aplicação de métodos quantitativos a problemas com elevado grau de complexidade. Recentemente, entretanto, novas ferramentas baseadas no uso do computador têm sido disponibilizadas, colocando, assim, a possibilidade de superação de alguns dos obstáculos em questão.

Nesse sentido, o trabalho tem como objetivo analisar a relação entre variáveis monetárias e a distribuição espacial das atividades produtivas em um mundo onde "a moeda importa". Mais especificamente, pretende-se, a partir desse exercício, lançar as bases para a construção de uma ferramenta que permita analisar a interação entre variáveis reais e monetárias, particularmente no que tange aos seus efeitos regionais.

$\mathrm{O}$ artigo encontra-se dividido da seguinte forma: além dessa introdução, no item 1, são feitas algumas breves considerações sobre os fundamentos teóricos e metodológicos; no item 2, apresenta-se o modelo a partir das suas equações fundamentais; no item 3, são apresentados e discutidos os principais resultados das simulações realizadas. No final, são tecidas algumas considerações a título de conclusão.

\section{Características teóricas/metodológicas do modelo}

A metodologia utilizada fundamenta-se na construção e implementação computacional de um modelo de simulação baseado em agentes (agent-based model)

(1) Como exemplo, a partir da literatura que trata dos efeitos regionais da política monetária, pode-se citar a abordagem monetarista de Beare (1976); Fishkind (1977), no âmbito da síntese neoclássica; More e Hill (1982), numa perspectiva novo-keynesiana; Carlino e Defina $(1996,1997)$, a partir da teoria novo-clássica. 
(Parunak; Savit; Riolo, 1998; Foley, 2002; Epstein; Axtell, 1996). Tais agentes tomam decisões de forma descentralizada em um ambiente incerto. A principal característica de um modelo baseado em Agentes Artificiais Adaptativos é a sua capacidade de gerar comportamentos emergentes, isto é, propriedades que surgem endogenamente e que não podem ser antecipadas no momento de definição do modelo. A construção e execução no computador dessas sociedades artificiais oferecem as seguintes vantagens (Holland; Miller, 1991): i) um arranjo experimental que permite a exploração das dinâmicas do sistema com completo controle de todas as condições; e ii) a oportunidade de checar, por plausibilidade, os vários desdobramentos dos comportamentos dos agentes.

No que se refere ao modelo propriamente dito, os agentes ativos são bancos e firmas. Um único grande banco, de abrangência nacional e com agências em cada uma das regiões representa o sistema financeiro, baseado no crédito, dessa economia artificial. Esses têm preferências pela liquidez (Keynes, 1985) regionalmente diferenciadas (Dow, 1993; Rodriguez-Fuentes; Dow, 2003) e devem decidir sobre a distribuição de seus recursos entre ativos de maior (títulos públicos) e de menor liquidez (crédito ao setor produtivo). As firmas são heterogêneas quanto à tecnologia e dependem do crédito bancário (capital monetário para a entrada e para capital de giro) para contratar trabalho (único insumo presente na função de produção) e efetuar a produção. Cada uma produz um único bem tradable assimetricamente diferenciado ${ }^{2}$, sendo o fator de diferenciação uma atribuição do consumidor, isto é, não pode ser conhecido ex ante pelo produtor.

Somando-se ao fato de que a entrada e a saída de firmas alteram recorrentemente as competitividades relativas, torna-se pouco provável que a curva de demanda possa ser conhecida ao ponto de possibilitar uma solução de equilíbrio pelas vias tradicionais de maximização. Por hipótese, a qualidade do produto como uma atribuição do consumidor juntamente com a alteração recorrente das competitividades relativas constituem elementos de incerteza. Propõe-se, assim, para a determinação da demanda, a utilização de um mecanismo alternativo empregado em modelos evolucionários. Esse se baseia numa versão discreta da replicator dynamic equation, inicialmente desenvolvida para o estudo da seleção biológica como uma formalização do princípio evolucionário de sobrevivência dos mais aptos de Darwin (Silverberg; Dosi; Orsenigo, 1988; Silverberg, 1997).

(2) O termo assimetricamente diferenciado é utilizado para distinguir a presente abordagem daquela encontrada nos modelos tradicionais a la Chamberlain, particularmente o modelo Dixit-Stiglitz (Dixit; Stiglitz, 1977). Tirole (1988, p. 100), por exemplo, numa crítica à utilização de uma função CES pelos modelos tradicionais de concorrência monopolística, observa que: "The latter utility function [CES] treats all differentiated products in a symmetric way". 
Por simplicidade, as regiões encontram-se alinhadas em um espaço finito. Como condição inicial, cada região começa com o mesmo número de firmas distribuídas aleatoriamente no espaço. O desempenho das economias regionais - e, consequentemente, das carteiras de ativos locais - é pertinente no processo de tomada de decisão do sistema bancário (preferência pela liquidez regionalmente diferenciada).

O modelo não inclui aprendizado tecnológico, o que significa que potenciais firmas deverão escolher a sua tecnologia em um conjunto dado. A operacionalização desse pressuposto é feita a partir da criação de um número finito de diferentes combinações dos parâmetros tecnológicos normalmente distribuídos, os quais caracterizam os projetos de investimento. Esses são: $A$ (parâmetro de diferenciação de produto), $T$ (coeficiente técnico de transformação) e $F$ (custo fixo). Tais projetos buscarão financiamento bancário (com respectivos encargos financeiros) para entrar no mercado. Vale lembrar que a firma conhece a sua função de produção - o coeficiente técnico $(T)$ e o custo fixo $(F)$-, entretanto, a qualidade do produto $(A)$ só será conhecida ex post mediante avaliação do consumidor, o que constitui um fator de incerteza. Isso significa que firmas heterogêneas terão resultados operacionais diferenciados, implicando, portanto, distintas condições de solvência financeira, o que afetará a preferência pela liquidez do sistema bancário, particularmente no que se refere à política de concessão de crédito nas diferentes regiões. Em suma, a dinâmica que se propõe a modelar baseia-se na implementação recursiva do seguinte algoritmo:

1. A firma demanda crédito bancário para entrar no mercado e para produzir;

2. A produção implica geração de emprego e renda e, dessa forma, a demanda potencial pelos bens ofertados;

3. Apuram-se as demandas individuais que, confrontadas com as respectivas quantidades ofertadas, determinam o resultado operacional e financeiro das firmas;

4. A tomada de decisão do setor bancário - determinação do spread e da oferta de crédito - baseia-se em variáveis locais (percepção de fragilidade financeira da economia regional);

5. O setor bancário apura o seu resultado operacional, determinando a liquidez do sistema, para o reinício do ciclo no item 1 .

A seguir, são apresentadas as equações fundamentais do modelo. 


\section{0 modelo ${ }^{3}$}

\subsection{O lado real da economia}

A quantidade total $(Q)$ ofertada pela firma $i$, localizada na região $j$, em cada período $t$ é dada pela sua função de produção, pela quantidade de insumo utilizado $(L)$ e pelos estoques $(V)$ eventualmente existentes:

$$
Q_{i, j, t}=T_{i, j}\left(L_{i, j, t}-F_{i, j}\right)+V_{i, j, t}
$$

A assimetria entre as firmas decorre do fato de que cada uma possui uma combinação específica dos parâmetros $F, T$ e $A$, sendo esses selecionados aleatoriamente a partir de uma distribuição normal, cujos parâmetros são definidos exogenamente. $\mathrm{O}$ conjunto das possibilidades tecnológicas corresponde, então, ao vetor de tecnologias do modelo. O grau de assimetria tecnológica entre as firmas é definido exogenamente mediante a determinação do grau de dispersão em torno dos valores médios dos referidos parâmetros.

O primeiro termo da equação 1 corresponde à função de produção da firma, a qual apresenta economias de escala. A diversidade tecnológica implica que quantidades distintas poderão ser produzidas a partir de uma mesma quantidade de insumo. No início de cada período de produção, cada firma deve possuir capital para contratar uma quantidade mínima de trabalhadores (escala mínima de produção), satisfazendo a condição $L_{i, j, t} \geq F_{i, j}$. Caso esta última não se verifique, ocorre a exclusão da firma do mercado.

A quantidade a ser produzida (produção desejada) em cada período é definida pela demanda esperada $\left(Q_{i, j, t}^{e}\right)$ (determinada por meio de expectativas formadas com base em observações passadas da sua demanda efetiva $\left(D_{i, j, t}\right)$ ), descontando-se os estoques $\left(V_{i, j, t}\right)$. Assim, a produção desejada $\left(Q_{i, j, t}^{d}\right)$ para o período corrente será dada por:

$$
\begin{array}{ll}
Q_{i, j, t}^{d}=Q_{i, j, t}^{e}-V_{i, j, t} & \text { se } \quad Q_{i, j, t}^{e}>V_{i, j, t} \\
Q_{i, j, t}^{d}=0 \quad \text { se } & Q_{i, j, t}^{e} \leq V_{i, j, t}
\end{array}
$$

Mediante a manipulação algébrica da função de produção, obtém-se o volume de trabalho $\left(L_{i, j, t}\right)$ necessário para a realização da quantidade $Q_{i, j, t}^{d}$. O salário regional $\left(W_{j, t}\right)$, por sua vez, eleva-se acima do piso salarial $\bar{W}$ quando a demanda regional por trabalho $\left(K_{j, t}\right)$ se eleva acima da oferta fixa $(\bar{L})$.

O preço de fábrica (mill price) é determinado a partir de uma regra de markup sobre o custo unitário:

(3) Em linhas gerais, o presente trabalho introduz a dimensão "espaço" no modelo apresentado por Paula (2013), que poderá ser consultado para o detalhamento de passagens específicas. 


$$
P_{i, j, t}=\frac{M k_{i, j, t}\left[\left(A_{i, j, t-1}^{D}+K_{i, j, t}^{L}\right)\left(1+r_{j, t}\right)+A_{i, j, t}^{P}\right]}{Q_{i, j, t}^{e}} ;
$$

sendo, $M k_{i, j, t} \geq\left(1+r_{j, t}\right)$.

Nota-se que os custos são dados pelos empréstimos contraídos $\left(K_{i, j, t}^{L}\right)$ à taxa de juros regional $\left(r_{j, t}\right)$, sendo $A^{D}$ e $A^{P}$, respectivamente, a dívida e o lucro acumulados, eventualmente herdados do período anterior. Dessa forma, espera-se que o preço determinado seja capaz de gerar uma receita igual ou maior que os custos financeiros devidos no período e ainda propiciar a remuneração do capital próprio. Por fim, a taxa de juros de empréstimo cobrada pelo banco $(r)$ corresponde à taxa básica $\left(i^{*}\right)$, definida exogenamente pela autoridade monetária, acrescida do spread bancário (z). Cabe observar que o spread tem caráter local, incorporando as expectativas do setor bancário com respeito à economia regional onde a empresa financiada se localiza.

Aos preços de fábrica são então incorporados os custos de transporte de modo a se obter os preços nos $r$ mercados regionais. Esses são dados por:

$$
P_{i, r, t}=\left(1+\xi d_{j}^{r}\right) P_{i, j, t}
$$

A equação (5) informa que, estando o produtor localizado na região $j$, o preço para o consumidor na região $r$ será o preço em $j$ acrescido dos custos de transporte de $j$ até $r$-consequentemente, quando $j=r, P_{i, r, t}=P_{i, j, t}$. Os referidos custos são definidos pela distância euclidiana $d$ multiplicada pelo coeficiente técnico $\xi$, que reflete a tecnologia de transporte vigente. Vale notar que esses não correspondem somente ao custo de deslocamento físico de uma mercadoria no espaço, mas sim ao custo de distribuição espacial do produto, ou seja, incluem custos de estocagem, transporte strictu sensu, cobrança, marketing, monitoramento de mercado etc. É certo que esses custos não são todos uma função da distância física entre mercados, mas, à guisa de simplificação, o utilizaremos nessa modelagem.

Dado que a qualidade do produto é uma atribuição do consumidor, a firma não conhece a sua curva de demanda de modo a obter uma solução de equilíbrio pelas vias tradicionais de maximização. Alternativamente, para a determinação da demanda, adota-se um mecanismo bastante utilizado em modelos evolucionários (Silverberg, Dosi; Orsenigo, 1988). No presente caso, pressupõe-se um processo interativo entre um indicador de competitividade e o market-share da firma. Esses são definidos, respectivamente, pelas equações 6 e 7 :

$$
C_{i, r, t}=\frac{1}{P_{i, r, t} M_{i, r, t} A_{i, j}} ;
$$

sendo, $\frac{d C}{d P}<0 ; \frac{d C}{d M}<0 ; \frac{d C}{d A}>0$ e $0<M<1$. 


$$
M_{i, r, t+1}=M_{i, r, t}\left[1+\lambda\left(\frac{c_{i, r, t}}{c_{r, t}}-1\right)\right]
$$

A equação 6 informa que a competitividade da firma $i$, localizada em $j$, no período $t$, em cada mercado local $r$ varia inversamente com o seu preço local $\left(P_{r}\right)$ e seu market-share nos respectivos mercados locais $\left(M_{r}\right)$ e que, quanto mais elevado for o parâmetro tecnológico $A$ (indicador da qualidade do produto), mais rígida será a curva de demanda individual, isto é, maior deverá ser a redução de preço necessária para aumentar a competitividade em um dado grau. Por outro lado, o crescimento de $M_{r}$ é determinado a partir de uma comparação entre a competitividade da firma e a competitividade média $\left(\bar{C}_{r, t}\right)$ das firmas que operam no mercado local $r$ no período $t$. Formalmente, a evolução de $M$ é descrita como uma Cadeia de Markov, sendo $\lambda$ definido exogenamente, determinando a velocidade com que $M$ varia em função de mudanças no diferencial de competitividade. Observa-se a existência de uma relação circular estabelecida entre as equações (6) e (7), impondo um limite ao crescimento das firmas ou, em outros termos, evitando uma situação de monopólio.

A demanda monetária da firma em cada mercado local é então definida como uma parcela da renda disponível regional $Y^{d}$ (especificada no item 2.3), proporcional ao seu market-share local e que, quando ponderada pelo preço praticado, estabelece a demanda quantidade. Consequentemente, a quantidade demandada total de cada bem $i$ produzido em $j$ no período $t$ é dada pelo somatório das demandas regionais no mesmo período, sendo essa expressa por:

$$
D_{i, j, t}=\sum_{j=1}^{r}\left[M_{i, r, t}\left(\frac{Y_{r, t}^{d}}{P_{i, r, t}}\right)\right]
$$

\subsection{O lado monetário da economia}

Uma vez determinadas as ofertas e as demandas individuais, ao final do período $t$, para cada firma $i$ localizada em $j$, é apurada uma receita total $\left(R_{i, j, t}=\right.$ $\left.P_{i, j, t} D_{i, j, t}\right)$. Espera-se que essa seja pelo menos o suficiente para a quitação dos débitos contraídos no período $\left(E_{i, j, t}\right)$, expressos por:

$$
E_{i, j, t}=\left(1+r_{j, t}\right)\left(A_{i, j, t-1}^{D}+K_{i, j, t}^{L}\right)
$$

É importante observar que o montante devido $\left(E_{i, j, t}\right)$ pode ser dividido em juros $\left(J_{i, j, t}\right)$ e amortizações $\left(A M_{i, j, t}\right)$, sendo esses definidos, respectivamente, por:

$$
\begin{aligned}
& J_{i, j, t}=r_{t}\left(A_{i, j, t-1}^{D}+K_{i, j, t}^{L}\right) \\
& A M_{i, j, t}=\left(A_{i, j, t-1}^{D}+K_{i, j, t}^{L}\right)
\end{aligned}
$$

Torna-se então possível introduzir a taxonomia minskiana dos regimes financeiros (Minsky, 1986). As firmas que obtiverem recursos suficientes para a quitação de seus débitos, encontrar-se-ão em uma posição Hedge. Entretanto, a diversidade tecnológica fará emergir outros tipos de endividamento, a saber: o 
Especulativo, em que a firma consegue pagar os juros sem, entretanto, amortizar o principal e o endividamento Ponzi, em que nem a amortização nem o pagamento dos juros são efetuados. Formalmente, tais possibilidades são expressas por:

$$
\begin{aligned}
& R_{i, j, t} \geq E_{i, j, t} ; \quad \text { Hedge } \\
& J_{i, j, t} \leq R_{i, j, t}<E_{i, j, t} ; \\
& R_{i, j, t}<J_{i, j, t} ; \quad \text { Especulativa }
\end{aligned}
$$

Quando uma firma não consegue pagar, na totalidade, os seus encargos financeiros, a quantia pendente é incorporada ao seu estoque de dívida. Como se observa pela equação (6), isso afetará positivamente o seu preço no período seguinte e, por conseguinte, a sua competitividade de forma inversa. A acentuação desse processo poderá resultar na exclusão da firma a partir do momento em que não for atendida a condição $L_{i, j, t} \geq F_{i, j}$. Bancos geralmente se empenham em estabelecer relações com seus clientes no intuito de reduzir a incerteza. Uma vez que constroem uma relação com um cliente, têm fortes incentivos para atender as demandas daquele cliente (Wray, 1992). Dessa forma, assume-se que o banco se prontificará a refinanciar firmas inadimplentes.

A partir do resultado operacional das firmas e, por conseguinte, de suas respectivas posições financeiras, torna-se possível a avaliação da qualidade da carteira de ativos do setor bancário, particularmente no que se refere à taxa de inadimplência sobre as operações de crédito. Essa pode ser considerada como uma medida do grau de fragilidade financeira percebida que, dadas as hipóteses do modelo, pode ser obtida para cada região, sendo expressa da seguinte forma:

$$
H_{j, t}=\sum_{i=1}^{n} \frac{\left(J_{i, j, t}^{e}+A M_{i, j, t}^{e}\right)-\left(J_{i, j, t}+A M_{i, j, t}\right)}{J_{i, j, t}^{e}+A M_{i, j, t}^{e}}
$$

O primeiro termo do numerador representa o total de pagamentos que deveriam ser realizados (esperados), e o segundo, os pagamentos efetivos, de modo que $0 \leq H \leq 1$. Mais especificamente, quanto maior for $H$, maior a percepção de fragilidade financeira do sistema.

Outro indicador pertinente para o setor bancário refere-se ao desempenho relativo dos ativos disponíveis dado pela equação:

$$
h_{j, t}=\frac{\left[\sum_{i=1}^{n}\left(J_{i, j, t}-X_{i, j, t}^{F}\right] / X_{j, t}^{C r}\right.}{B_{t} / X_{t}^{B}}
$$

O indicador $h$ é uma variável local. Esta compara os rendimentos percentuais das aplicações em crédito na região $j$ com o rendimento percentual das aplicações em títulos, onde $X_{j, t}^{C r}$ representa o total concedido em financiamentos na região $j \mathrm{e}$ $X_{i, j, t}^{F}$, a perda de capital decorrente da falência da firma $i$ da região $j$ no período corrente; o denominador $B_{t}$ refere-se ao rendimento do total aplicado em títulos $X_{t}^{B}$. 
Com base nos indicadores definidos acima, é possível formular um modelo de tomada de decisão por parte dos bancos em uma economia multirregional. As principais decisões referem-se a: i) volume de recursos direcionados aos financiamentos ao setor produtivo em cada região; ii) determinação do spread bancário em cada região; e iii) financiamento à entrada de firmas. A seguir, são especificadas as referidas rotinas:

\section{i)Mercado regional de crédito}

Ao final de cada período, o setor bancário disporá de um volume de recursos líquidos definido pelos montantes aplicados em títulos e financiamentos, somados aos seus respectivos rendimentos. Por hipótese, novamente esse montante deverá ser redistribuído entre títulos e financiamentos no período seguinte, reiniciando-se o ciclo. Propõe-se que esse processo de tomada de decisão seja formalizado, calculando-se a parcela que caberá a cada região como uma proporção das respectivas demandas regionais e deduzindo-se posteriormente, de cada uma dessas, uma parte que será direcionada à aplicação em títulos. A oferta regional de crédito é então definida da seguinte forma:

$$
X_{j, t}^{C}=\frac{K_{j, t}^{L}}{K_{t}^{L T}}\left(1-\mu_{j, t}\right) X_{t}^{T}
$$

onde $K_{j, t}^{L}$ é a demanda regional de crédito; $K_{t}^{L T}$ é a demanda total da economia; e $X_{t}^{T}$ são os recursos financeiros totais do setor bancário.

Atenção especial deve ser dada a $\mu_{j, t}$, que se refere ao percentual para aplicação em títulos. Esse é um parâmetro local e varia entre as regiões em função dos respectivos graus de solidez financeira regional percebida. Assim, quando as finanças regionais se debilitam, é provável que a região em questão receba menos recursos que o demandado. $\mathrm{O}$ referido parâmetro pode então ser especificado como uma função de $H$ da forma como se segue:

$$
\mu_{j, t+1}=\left(H_{j, t}\right)^{\rho}
$$

sendo $\rho>0$ definido exogenamente.

\section{ii) Determinação do spread}

Alguns trabalhos têm relatado o spread bancário (z) como uma uma função direta do nível de fragilidade financeira percebida (Lima; Freitas, 2007). Nesse sentido, a trajetória do spread é tomada como uma versão suavizada da trajetória de $H$, tal como se segue:

$$
Z_{j, t}=\alpha H_{j, t-1}+(1-\alpha) H_{j, t}(19),
$$

sendo $0<\alpha<1$ definido exogenamente. 
Uma vez determinado o spread, esse é acrescido à taxa básica, definindo, assim, a taxa de juros de empréstimo.

\section{iii) Financiamento à entrada}

Até o momento, foi considerado o financiamento ao capital de giro. Não obstante, o financiamento à entrada é essencial no que tange à questão locacional. Os projetos de investimento informam sobre a localização desejada, e esse aspecto é pertinente no processo decisório do agente financeiro. Uma formalização possível desse processo se baseia no seguinte algoritmo:

1. A firma entrante informa o preço que espera praticar (preço potencial), estando localizada em $j$; esse é tomado como um indicador da competitividade esperada $\left(P_{i, j}^{F}\right)$;

2. Um nível mínimo de competitividade desejada é estipulado pelo setor bancário, também representado por um preço $\left(P_{j, t}^{B}\right)$;

3. O financiamento é concedido se o preço potencial do projeto de investimento for igual ou menor que aquele estipulado pelo banco, isto é:

$$
P_{i, j}^{F} \leq P_{j, t}^{B}
$$

A entrada implica a necessidade de se obter um capital mínimo suficiente para a obtenção de trabalho ao nível da escala mínima de produção $\left(F_{i, j}\right)$ e ao salário local vigente $\left(W_{j, t}\right)$. Caso seja demandado um volume maior, dois efeitos devem ser considerados: ganhos de escala e elevação dos encargos financeiros, cujas respectivas participações na determinação do preço potencial são, a priori, indefinidas. Expectativas positivas com respeito à economia e, particularmente, com respeito à localização escolhida, podem ensejar uma demanda de capital acima do nível mínimo. Inicialmente, define-se o capital mínimo como:

$$
K_{i}^{*}=\gamma_{j} F_{i} W_{j} ; \quad \gamma>1
$$

Com $K^{*}$ é possível adquirir $L^{*}$ que, substituído na função de produção e posteriormente na equação de preços, resulta em:

$$
P_{i, j}^{F}=M k_{i, j}\left(\frac{\gamma_{j, t}}{\gamma_{j, t}-1}\right)\left(\frac{\left(1+r_{j, t}\right) W_{j, t}}{T_{i}}\right)
$$

A equação (22) fornece o preço potencial, como um indicador da competitividade esperada para cada uma das localizações alternativas, determinado: i) pela tecnologia de processo da firma $(T)$; ii) pela estratégia de precificação da firma entrante $(M k)$; iii) pelos fatores particulares a cada região, quais sejam, o salário nominal $(W)$ e a taxa de juros de empréstimo $(r)$; e iv) pelo indicador de expectativas 
$\gamma$. Este último pode ser definido de forma simples como uma função da participação da renda regional $\left(Y_{j, t}\right)$ na renda nacional $\left(Y_{t}^{T}\right)$, tal como se segue:

$$
\gamma_{j, t}=\delta\left[1+\left(\frac{Y_{j, t}}{Y_{t}^{T}}\right)\right]^{\psi}
$$

sendo $\delta>1$ e $\quad 0 \leq \psi<1$.

Os preços potenciais se diferenciarão entre as diversas localidades em função das variáveis locais presentes na sua especificação, cabendo destacar a presença da taxa de juros de empréstimo como um fator locacional, papel tradicionalmente restrito às variáveis reais.

Para se chegar a uma decisão sobre a localização ótima, é preciso considerar os preços que se espera praticar não apenas na região sede, mas em todas as demais, dado que se trata de um bem tradable. Para cada localização alternativa haverá então um vetor de preços locais formado por todos os preços locais potenciais, que incluem os custos de transporte. A título de simplificação, médias aritméticas simples de cada um desses conjuntos de preços serão tomadas como uma proxy da competitividade esperada. O menor valor entre esses $P_{i, j, t}^{F *}$ determinará a localização ótima.

No que tange aos critérios do setor bancário para a concessão do crédito, adota-se aqui, a título de simplificação, uma rotina que consiste em comparar os rendimentos passados dos dois ativos disponíveis (crédito e títulos). Deve-se lembrar que o indicador dessa relação é dado pela equação 16, que determinará a postura do setor bancário da seguinte forma:

$$
P_{j, t}^{B}=\left\{\begin{array}{c}
\infty \quad \text { se } \quad h_{j, t-1}>0 \\
\frac{\bar{P}_{t-1}}{\sigma\left(h_{j, t-1}^{t-k}\right)} \text { se } \quad h_{j, t-1} \leq 0 .
\end{array}\right.
$$

$\mathrm{Na}$ equação 24a, a oferta de crédito é infinitamente elástica, condizente com o bom desempenho do ativo crédito. Em 24b, o numerador é dado pela média dos preços regionais e o denominador, pelo desvio padrão da variável $h$ no intervalo ( $t$ $1, t-k)$, onde $k$ é o número de períodos passados considerado. A variabilidade de $h$, medida pelo seu desvio padrão, é tomada como uma medida do grau de instabilidade do sistema. Ademais, quanto mais elevado o parâmetro $k$, maior a "memória" do setor financeiro com respeito às diferentes fases do ciclo econômico. Quando o comportamento do sistema é estável, $h$ tende a ser baixo, e vice-versa. A flexibilidade na concessão de crédito é inversamente relacionada com $P^{B}$.

Finalmente, a entrada da firma ocorre se é atendida a condição representada pela equação 20 . 


\subsection{Política econômica e renda disponível}

A renda agregada regional $\left(Y_{j, t}\right)$ é composta pela massa salarial repassada das firmas aos trabalhadores $\left(W_{j, t} L_{i, j . t}\right)$ e por uma eventual "poupança" $\left(S_{j, t}\right)$, sendo representada por:

$$
Y_{j, t}=\sum_{i=1}^{n}\left(W_{j, t} L_{i, j, t}+S_{i, j, t-1}\right)
$$

A renda nacional é então dada pelo somatório das rendas das $r$ regiões $\left(Y_{t}^{T}=\right.$ $\sum_{r=1}^{r} Y_{j, t}$ ). A equação 25 supõe que toda renda é alocada para o consumo. A variável $S$ deve então ser entendida como "renda não gasta", que se verifica ao nível de cada firma quando a quantidade demandada $\left(D_{i}\right)$ supera a quantidade ofertada $\left(Q_{i}\right)$. Nesse caso, a renda não gasta em um período é transferida para o período seguinte (postergação de gasto). Finalmente, de cada renda regional, deduz-se a tributação para a obtenção da renda disponível.

Por simplicidade, considera-se uma política de taxa de juros fixa e orçamento equilibrado, de modo que, as políticas fiscal e monetária deverão se ajustar para atingir essa meta. Essa opção implica uma tributação direta sobre a renda, cuja alíquota $(\beta)$ varia no sentido de garantir a igualdade entre arrecadação e remuneração dos títulos, da seguinte forma:

$$
\beta_{t}=\frac{\left(i^{*}\right) X_{t}^{B}}{Y_{t}}
$$

Para a composição do montante arrecadado, uma parcela $(\beta)$ é deduzida de cada renda regional, definindo, assim, a renda disponível regional $\left(Y^{d}\right)$, da forma como se segue:

$$
Y_{j, t}^{d}=\left(1-\beta_{t}\right) Y_{j, t}
$$

Como se pode observar na equação 26 , a alíquota tributária se altera a cada período de modo a manter o orçamento público em equilíbrio. Dessa forma, a título de simplificação, as políticas econômicas são endogeneizadas como uma função das decisões do sistema financeiro sobre o volume das aplicações em títulos a cada período.

\section{Evolução do sistema}

No exercício que se segue é simulado o modelo básico com parâmetros e condições iniciais definidos no Quadro 1. Posteriormente, algumas possibilidades serão exploradas a partir de variações na parametrização inicial. Cabe ressaltar que pesquisas empíricas com vistas à calibragem do modelo constituem uma etapa posterior da presente investigação, de modo que, por ora, serão utilizados parâmetros considerados plausíveis. O software utilizado é o Netlogo 3.1.5 (Wilensky, 1999). 
Quadro 1

Parâmetros e Condições Iniciais do modelo

\begin{tabular}{|c|c|c|}
\hline \multicolumn{3}{|l|}{ Parâmetros } \\
\hline & $\mathrm{n}^{\mathrm{o}}$ de regiões & 50 \\
\hline & $\mathrm{n}^{\mathrm{o}}$ de tecnologias disponíveis & 1000 \\
\hline Assimetria & grau de heterogeneidade tecnológica & 0,60 (desvio padrão) \\
\hline$A$ & parâmetro de diferenciação de produto & 0,6 (média) \\
\hline$T$ & coeficiente técnico de transformação & 0,2 (média) \\
\hline $\boldsymbol{F}$ & custo fixo & $1,0 \quad$ (média) \\
\hline$i^{*}$ & taxa básica de juros & 0,01 \\
\hline $\boldsymbol{W}$ & piso salarial & 1 \\
\hline $\bar{L}$ & força de trabalho regional & 40 \\
\hline$\xi$ & tecnologia de transporte (eq. 6) & 0,01 \\
\hline $\boldsymbol{\delta}$ & parâmetro (eq. 26) & 3 \\
\hline$\psi$ & parâmetro (eq. 26) & 0.001 \\
\hline$\alpha$ & parâmetro (eq. 22) & 0,99 \\
\hline$\rho$ & parâmetro (eq. 21) & 4 \\
\hline$\lambda$ & velocidade de ajustamento da demanda (eq. 10) & 0,004 \\
\hline $\boldsymbol{k}$ & "memória" do setor bancário (eq. 27b) & 2 \\
\hline \multicolumn{3}{|c|}{ Condiç̃es Iniciais } \\
\hline & $\mathrm{n}^{\circ}$ inicial de firmas no mercado & 400 \\
\hline $\boldsymbol{X}$ & volume de capital do banco & 2000 \\
\hline$M$ & market-share da firma & $1 /\left(n^{\circ}\right.$ de firmas $)$ \\
\hline$C$ & competitividade da firma & 1 \\
\hline$r$ & taxa de juros de empréstimo & 0,01 \\
\hline$M k$ & mark-up & 1,2 \\
\hline
\end{tabular}

Fonte: Elaboração própria

\subsection{Dinâmica regional em um modelo com especulação financeira e diversidade produtiva}

Essa seção tem como objetivo fornecer uma caracterização geral da evolução do sistema proposto, ao nível agregado e ao nível regional. A simulação foi realizada para 600 períodos a partir da parametrização apresentada no Quadro 1. Cada região começa com um total de 8 firmas, entretanto, a diversidade tecnológica implicará que o volume de crédito, emprego e renda seja diferente entre essas.

Inicialmente, é possível observar na Figura 1, que representa a renda agregada, a ocorrência de dois ciclos econômicos cujas fases de depressão são verificadas, respectivamente, por volta dos períodos 200 e 400. 
Figura 1

Evolução da renda agregada



Fonte: Elaborado pelo autor a partir dos resultados da simulação.

A evolução do número de firmas na economia (Figura 2) tem como principal característica uma descontinuidade observada por volta de $t=300$. Estabelecendose esse ponto como um divisor entre os dois ciclos, nota-se uma tendência crescente no número de empresas presentes no mercado nos primeiros momentos de cada fase.

Figura 2

Evolução do número de firmas

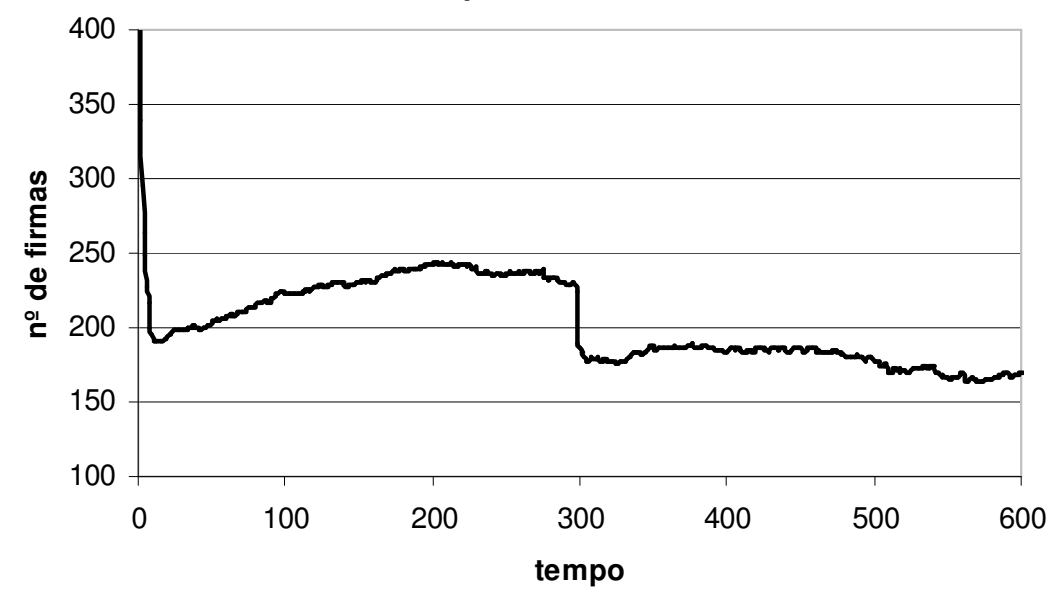

Fonte: Elaborado pelo autor a partir dos resultados da simulação.

A Figura 3 representa a evolução da distribuição dos recursos totais disponíveis do sistema bancário entre os ativos crédito e títulos públicos. Observase uma correlação inversa entre as variáveis em questão, bem como uma correlação direta entre o volume de crédito e a renda agregada. Esta última, particularmente, é de 0,731 . 
Figura 3

Alocação dos recursos financeiros

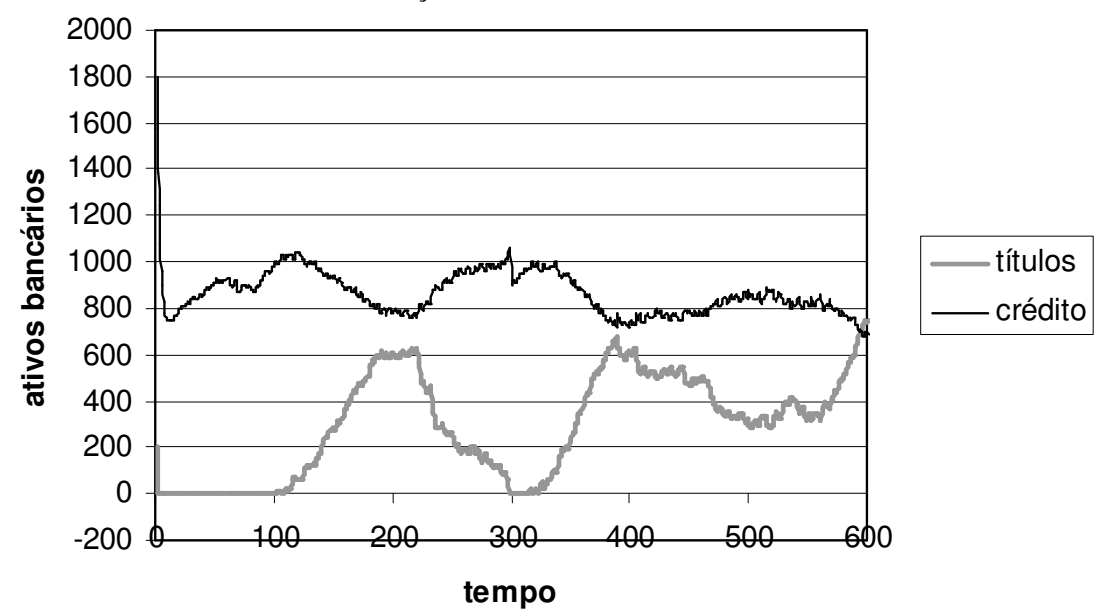

Fonte: Elaborado pelo autor a partir dos resultados da simulação.

A Figura 4 representa as alterações do grau de solidez financeira do sistema durante o período de simulação. Especificamente, ilustra a evolução, ao longo do tempo, do percentual de empresas situadas em cada um dos regimes financeiros (hedge, especulativo e Ponzi). Comparando-a com a Figura 1, é possível notar que as fases de elevação do grau de fragilidade financeira estão associadas aos períodos de recessão/depressão, sendo o inverso também válido.

Figura 4

Distribuição das firmas entre os regimes financeiros (\%)

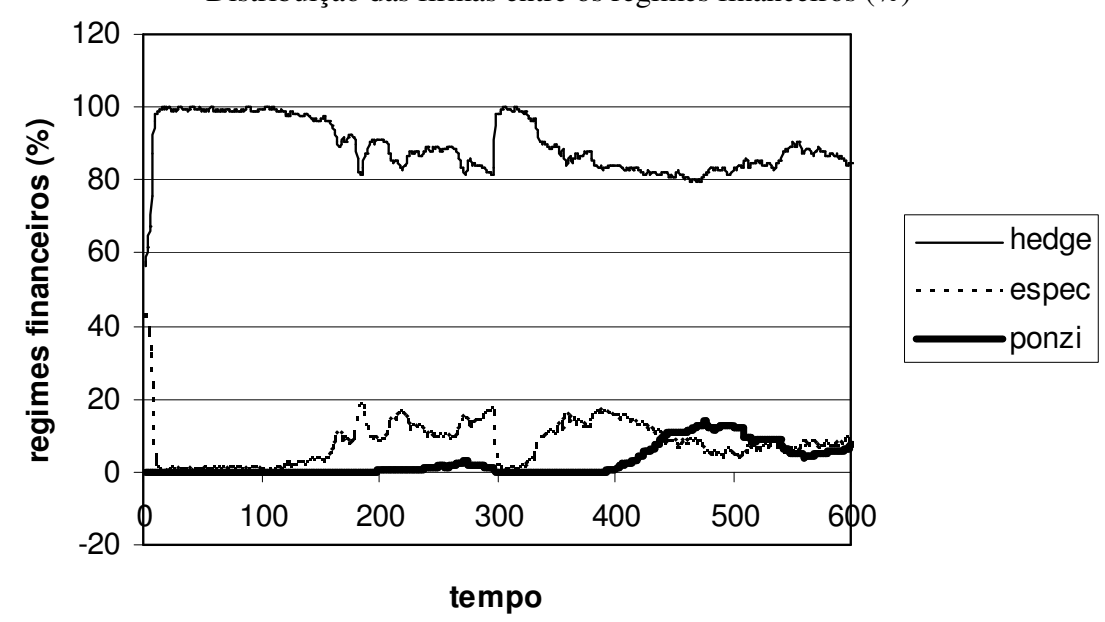

Fonte: Elaborado pelo autor a partir dos resultados da simulação.

Ainda, na Figura 4, observa-se que o processo de fragilização financeira é acompanhado de uma redução de empresas especulativas e um aumento de empresas 
Ponzi. Esse resultado é compatível com a elevação do spread (Figura 5), que acompanha o aumento da necessidade de financiamento das firmas (fragilização financeira). Como essa ação debilita ainda mais as firmas com elevado passivo, as duas variáveis evoluem sob causação mútua e cumulativa.

Figura 5

Spread médio

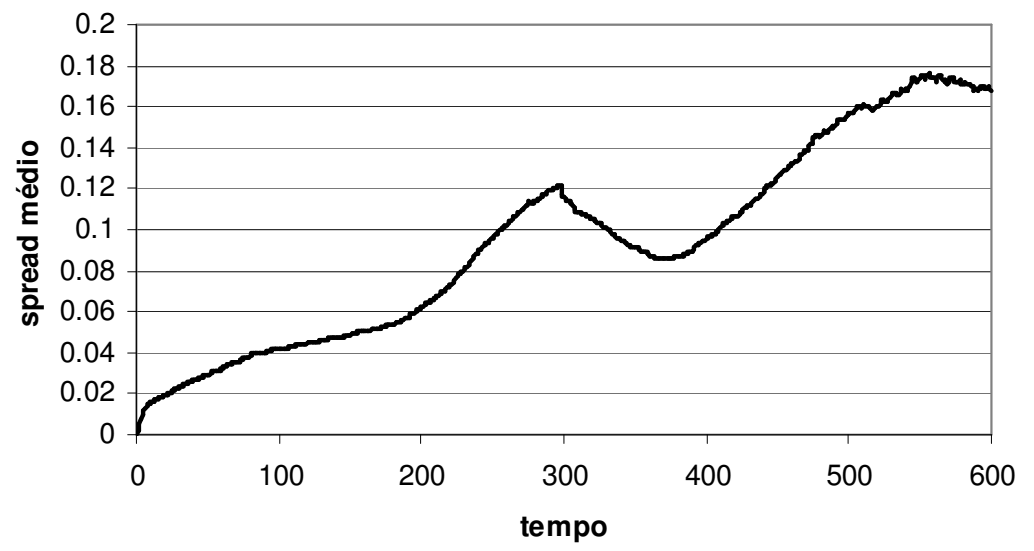

Fonte: Elaborado pelo autor a partir dos resultados da simulação.

No que se refere à sua dimensão espacial, o sistema apresenta uma tendência à concentração. Nota-se que, ao final do período de simulação $(\mathrm{t}=600)$, as regiões 24 e 25 respondem, respectivamente, por $28,12 \%$ e $21,35 \%$ da renda agregada. O mesmo padrão pode ser observado quando a variável em questão é o emprego regional (Figura 6).

Figura 6

Emprego regional $(\mathrm{t}=600)$

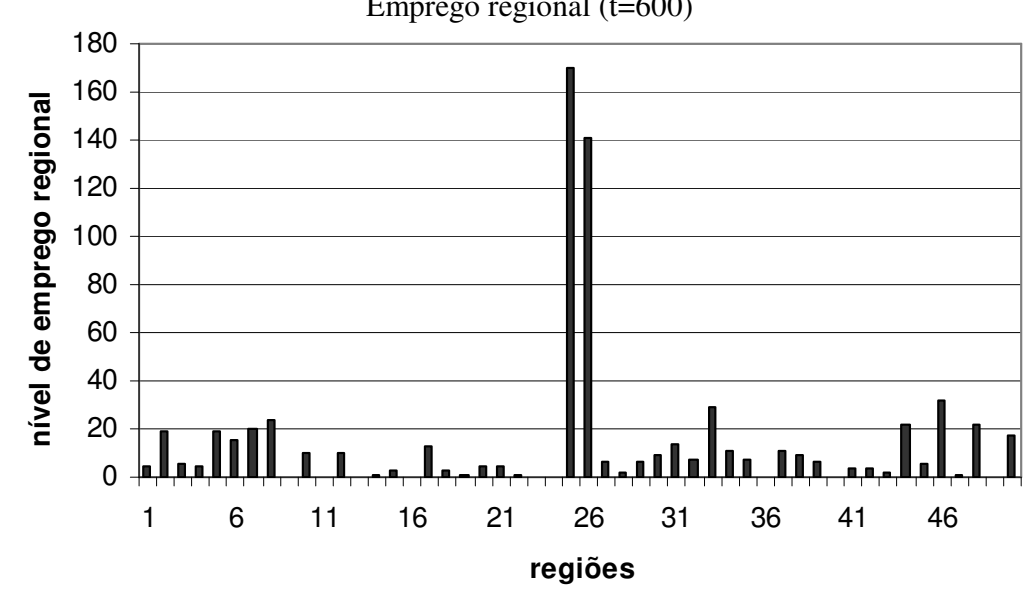

Fonte: Elaborado pelo autor a partir dos resultados da simulação. 
Finalmente, a Figura 7 mostra que, nos dois grandes centros (regiões 24 e 25), o spread bancário tem seus menores valores. Consequentemente, as taxas de juros de empréstimo também estão entre as menores.

Figura 7



Fonte: Elaborado pelo autor a partir dos resultados da simulação.

\subsection{Reprodução de fatos estilizados}

Uma regularidade em economia regional amplamente destacada, principalmente pela sua consistência estatística, refere-se à denominada Lei de Zipf, ou regra da ordem de tamanho. De acordo com essa, quando cidades são ordenadas por tamanho, há uma relação log-linear entre o tamanho e a posição das cidades no ranking (Isard, 1956; Rosen; Resnick, 1980). Mais especificamente, a magnitude do coeficiente angular (na forma linear) dessa relação funcional, conhecido como expoente de Pareto (na forma polinomial), é igual à unidade.

Geralmente, o tamanho populacional é utilizado como critério de ordenação. Nos exercícios que se seguem será utilizado o nível de emprego regional como uma proxy dessa variável. A Figura 8 ilustra a relação entre ordem e tamanho da economia regional, utilizando-se de dados gerados por simulações em diferentes períodos. $\mathrm{O}$ período 1 foi selecionado para efeito de comparação, já que, nesse, as dotações regionais de recursos são resultado de uma distribuição aleatória estabelecida como condição inicial. O período 100 é quando tem início a fragilização financeira, que atinge o seu auge por volta do período 290, implicando a descontinuidade observada na Figura 2, no período 306. À medida que o sistema evolui, nota-se uma mudança de inclinação nos gráficos, indicando que a distribuição aleatória inicial tende para uma distribuição de Pareto. Não obstante, a passagem pela fase de ruptura, entre os períodos 290 e 306, parece não afetar significativamente a distribuição de Pareto. 
Figura 8

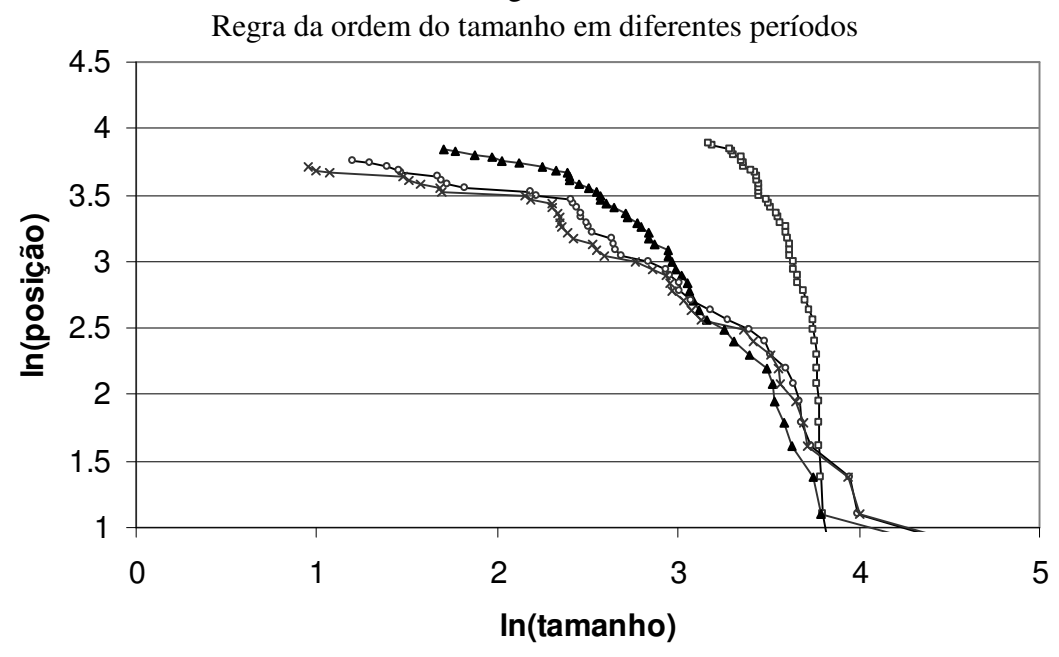

$\multimap \mathrm{t}=1 \multimap \mathrm{t}=100 \multimap \mathrm{t}=290 \multimap \mathrm{t}=306$

Fonte: Elaborado pelo autor a partir dos resultados da simulação.

Na Tabela 1, são apresentados os expoentes de Pareto para os períodos selecionados.

Tabela 1

Evolução do expoente de Pareto

\begin{tabular}{cccc}
\hline Período & Coeficiente & Desvio padrão & $\mathrm{R}^{2}$ \\
\hline 1 & -4.2607 & 0.3098 & 0.801 \\
100 & -1.2522 & 0.0530 & 0.926 \\
290 & -0.9076 & 0.0468 & 0.902 \\
306 & -0.8494 & 0.0476 & 0.891 \\
\hline
\end{tabular}

Fonte: Elaborado pelo autor a partir dos resultados da simulação.

Os valores foram calculados via Mínimos Quadrados Ordinários - MQO. Todos os coeficientes se mostraram significativos a $1 \%$. Observa-se que, para o período 1 , o coeficiente de Pareto diverge significativamente do valor esperado, qual seja, igual à unidade. Esse resultado, entretanto, decorre do caráter aleatório da distribuição inicial de firmas. Note, porém, que, com a evolução do sistema, o referido parâmetro se aproxima de $\mid 1$ |.

Essa sessão procurou demonstrar que o modelo proposto é capaz de reproduzir um importante fato estilizado em economia regional, qual seja, a relação log-linear entre tamanho e posição em um ranking decrescente de regiões. Há controvérsias se essa é uma condição necessária no que se refere à consistência do modelo. Alguns autores ressaltam que uma história plausível sobre o processo que gera a regra da ordem de tamanho permanece como uma lacuna na teoria econômica 
(Fujita; Krugman; Venables, 1999). Outros, entretanto, consideram que qualquer modelo que tente explicar o crescimento de cidades, para ser validado, deve reproduzir algo como a regra da ordem do tamanho (Garbaix, 1999).

\subsection{Spread bancário como fator locacional}

Uma das hipóteses do presente trabalho atesta que, num contexto de moeda não neutra, variáveis monetárias podem influenciar a distribuição espacial dos recursos. No sentido de avaliar essa proposição, uma modificação será feita com respeito à parametrização utilizada até o momento, apresentada no Quadro 1. Essa se refere à atribuição de valor zero para os parâmetros $\psi$ e $\xi$ e à fixação dos salários regionais em $\bar{W}=1$. Assim procedendo, elimina-se do modelo os efeitos dos fatores locacionais clássicos, a saber: os retornos crescentes decorrentes da diversificação ou especialização, os custos de transporte e as variações salariais inter-regionais. A escolha da localização passa a ser ditada basicamente pelas variações do spread bancário regional. Vale lembrar que o spread bancário é definido pela percepção do banco com respeito à solidez financeira da sua carteira de ativos na região em questão, isto é, uma variável comportamental definida localmente.

Figura 9



Fonte: Elaborado pelo autor a partir dos resultados da simulação.

Tabela 2

Evolução do Coeficiente de Pareto, quando $\xi=0, \psi=0$ e $\bar{W}=1$

\begin{tabular}{cccc}
\hline Período & Coeficiente & Desvio padrão & $\mathrm{R}^{2}$ \\
\hline 200 & -1.1375 & 0.0825 & 0.8121 \\
400 & -0.9837 & 0.0530 & 0.8891 \\
600 & -0.9711 & 0.0638 & 0.8496 \\
\hline
\end{tabular}

Fonte: Elaborado pelo autor a partir dos resultados da simulação. 
Como se pode observar, os resultados da simulação indicam que a concentração regional pode emergir a partir de comportamentos localmente diferenciados por parte dos agentes do setor financeiro. Esse fenômeno pode ser explicado pelo fato de que pequenas diferenças nas condições iniciais desencadeiam processos cumulativos que resultam na concentração da produção e da renda em locais específicos em detrimento de outros. Particularmente, quando a carteira de ativos do banco em uma região se revela ligeiramente mais rentável que em outras, um menor spread bancário será praticado, o qual, por sua vez, estará associado a um nível de competitividade regional mais elevado. Tudo mais permanecendo constante, as variáveis em questão evoluirão sob causação circular, que, em última instância, acelera o crescimento do emprego e da renda na referida região. Esse processo é ainda acentuado pela entrada de firmas cujas expectativas de retorno são positivamente afetadas pelas condições financeiras relativamente mais favoráveis da região em questão.

Como nesse exercício não há, a priori, uma força centrífuga, poderia se imaginar que estaria em curso uma solução trivial, isto é, a concentração da produção em um único ponto. No entanto, esse não foi o resultado encontrado no exercício acima. A explicação para esse comportamento reside na própria hipótese da fragilidade financeira: a elevação crescente do número de firmas, garantida, por um lado, pela atratividade das baixas taxas de juros de empréstimo e, por outro, por um sistema bancário essencialmente especulativo, em determinado momento, conduzirá à fragilização financeira do sistema econômico regional, implicando uma reversão nas condições de financiamento até então caracterizadas pela flexibilidade. O agravamento desse quadro, tal como já analisado, levará um número considerável de firmas à falência num espaço definido de tempo, o que caracteriza a crise financeira. Esse se constitui no fator limitador do crescimento regional. Em suma, baixos níveis de spread bancário estimulam a concentração, mas, ao mesmo tempo, abrem espaço para a fragilização financeira que, em última instância, impede o crescimento indefinido da economia regional. Esse mecanismo pode se constituir numa das formas a partir da qual uma variável financeira pode ter efeitos sobre a organização do espaço econômico.

\subsection{Instabilidade financeira como fator de seleção tecnológica}

O objetivo dessa seção é analisar os efeitos das crises sistêmicas sobre as economias regionais. A Figura 2 mostra que há uma redução significativa do número de firmas no auge da crise financeira. Um dado de interesse diz respeito a possíveis mudanças na composição setorial da economia, bem como em suas particularidades locais. Nesse sentido, com base nos dados da simulação conduzida no item 3.1, obteve-se a Figura 10, que ilustra a evolução do valor médio dos parâmetros 
tecnológicos $A$ (parâmetro de diferenciação de produtos), $T$ (coeficiente técnico de transformação) e $F$ (custo fixo) das firmas em operação.

Figura 10

Evolução dos parâmetros tecnológicos A, T e F (média aritmética)



Fonte: Elaborado pelo autor a partir dos resultados da simulação.

A principal observação refere-se a uma alteração significativa nas médias dos parâmetros $A$ (que se eleva) e $F$ (que se reduz) quando da ocorrência da crise financeira por volta do período 300. É importante notar que a elasticidade-preço da equação 6 é dada por $\epsilon=-1 / P C M^{A}$. Nesse caso, a demanda é mais inelástica quanto mais elevado for o parâmetro tecnológico $A$. Observou-se também que valores relativamente baixos do parâmetro $F$ caracterizaram as firmas que superaram a crise. Em suma, as firmas com reduzidas economias de escala e com elevada diferenciação de produto foram menos afetadas pela crise econômica.

No sentido de avaliar as particularidades locais do processo acima relatado, foram definidas três classes de regiões de acordo com as respectivas participações percentuais na renda agregada, a saber: (I) regiões centrais: $\bar{Y} \geq 10 \%$; (II) regiões intermediárias: $2 \% \leq \bar{Y}<10 \%$; e (III) regiões periféricas: $\bar{Y}<2 \%$. O objetivo é observar, em cada classe de região, o comportamento dos respectivos valores médios dos parâmetros $A$ e $F$ (já que o parâmetro $T$ não apresentou alterações significativas) entre os períodos $\mathrm{t}=290$ e $\mathrm{t}=306$, respectivamente, antes e depois do ponto de ruptura. 
Tabela 3

Evolução dos parâmetros tecnológicos para diferentes classes de regiões

\begin{tabular}{lcccccc}
\hline & A médio & & & \multicolumn{3}{c}{$F$ médio } \\
\hline & Centro & Intermédio & Periferia & Centro & Intermédio & Periferia \\
& $(I)$ & $(I I)$ & $(I I I)$ & $(I)$ & $(I I)$ & $(I I I)$ \\
\hline $\mathrm{t}=290$ & 0.6814 & 0.8204 & 0.5872 & 0.6060 & 0.8538 & 0.6038 \\
$\mathrm{t}=306$ & 0.7160 & 0.9437 & 0.6828 & 0.6294 & 0.7869 & 0.4967 \\
Variação $(\%)$ & 0.051 & 0.150 & 0.163 & 0.039 & -0.078 & -0.177 \\
\hline
\end{tabular}

Fonte: Elaborado pelo autor a partir dos resultados da simulação.

A Tabela 3 evidencia uma mudança na composição setorial das economias regionais, particularmente quanto às regiões não centrais. Especificamente, as informações fornecidas podem ser sintetizadas em: i) as variações menos significativas, quanto a ambos os parâmetros, referem-se às regiões da classe I; ii) o parâmetro $A$ variou significativamente nas regiões classe II e III, enquanto a variação de $F$ foi mais expressiva apenas nas regiões classe III; iii) a variação de $F$ referente às regiões classe $\mathrm{I}$, ainda que pouco expressiva, apresenta sinal oposto ao observado no agregado (ver Figura 10) e, especificamente, nas regiões II e III (Tabela 3). A primeira conclusão que decorre das referidas observações é que as regiões centrais se tornaram relativamente mais diversificadas ou, de forma equivalente, as regiões periféricas (II e III) se tornaram mais especializadas; isso porque o aumento do valor médio de $A$ nestas últimas indica que, no processo de exclusão em massa observado durante a crise sistêmica, as firmas com baixa diferenciação de produto foram as mais afetadas. No centro, por sua vez, firmas com os mais variados graus de diferenciação de produto demonstraram igual capacidade de sobrevivência, sugerindo que a localização na região central representa, por si só, uma vantagem competitiva.

Da mesma forma, o comportamento do valor médio de $F$ evidencia a importância de uma localização próxima aos grandes centros para firmas com elevadas economias de escala. Enquanto a renda é elevada (até t $=290$ ), firmas com tais características conseguem sobreviver em economias periféricas. Com a reversão cíclica (após $t=306$ ), o decréscimo da renda implica a necessidade de se buscar novos mercados, o que, por seu turno, acarreta custos de transporte. Ademais, como já discutido, economias periféricas geralmente estão associadas a elevadas taxas de juros de empréstimo. Esses fatores em conjunto têm impacto significativamente mais elevado sobre empresas mais sensíveis à escala de produção. Em suma, os efeitos deletérios de uma crise financeira com as características analisadas no presente trabalho parecem se fazer sentir de forma mais aguda em regiões periféricas, o que se constitui num elemento de disparidade regional. 


\section{Considerações finais}

Procurou-se analisar as formas pelas quais variáveis financeiras podem afetar o sistema econômico na sua dimensão espacial. A característica fundamental do tipo de sistema considerado refere-se a uma instabilidade gerada endogenamente no âmbito da relação entre os sistemas financeiro e produtivo. Os exercícios realizados indicaram que a distribuição espacial dos recursos produtivos e, consequentemente, da renda e do emprego, pode ser significativamente impactada ao longo do processo de emergência e superação de uma crise financeira. Particularmente, a comparação entre a configuração inicial e final do sistema ao longo das simulações corrobora a hipótese da existência de processos de causação circular cumulativa, resultando em aumento das disparidades regionais (Kaldor, 1970; Myrdal, 1960).

O modelo sugere também um mecanismo formal a partir do qual o spread bancário é capaz de influenciar a distribuição espacial dos recursos. Como fator locacional, o papel do spread é ambíguo: quando em níveis baixos, exerce força centrípeta, induzindo ao crescimento; com a fragilização financeira que se segue, se eleva, precipitando a reversão cíclica e atuando como força repulsora.

Em linhas gerais, os resultados apontam para a importância de se considerar a introdução de variáveis financeiras nas políticas econômicas regionais, bem como de elementos locais na política monetária. A esse respeito, embora investigações mais aprofundadas sejam necessárias, Menezes e Crocco (2005) sugerem algumas diretrizes, a saber: i) determinação de taxas de reservas compulsórias menores para as regiões menos desenvolvidas, bem como para bancos de pequeno e médio porte, destacando que propostas dessa natureza já foram apresentadas, inclusive com o surgimento de leis tratando do assunto, muito embora, na prática, não se tenham efetivado; ii) regulamentação bancária que verse sobre a atuação de bancos regionais, tanto públicos quanto privados, partindo do pressuposto de que bancos com sedes regionais tendem a gerar mais crédito regional, uma vez que possuem informações mais sólidas sobre a economia local, ao mesmo tempo que teriam incentivos para se preocupar mais com o desempenho das empresas ali presentes; e iii) criação de bancos municipais, a exemplo do que ocorre em países como França e Japão, ou a formação de mercados municipais de títulos, tal como nos Estados Unidos, onde funcionam como principal fonte de financiamento dos governos locais. Além disso, depois da crise financeira de 2008, uma ampla discussão sobre o controle de capitais voltou à tona nos fóruns internacionais. Nesse contexto, é possível questionar se não seria o caso de se pensar em uma regulamentação que também controlasse o fluxo de capital entre regiões de um mesmo país.

É importante ressaltar que este trabalho deve ser entendido como uma etapa inicial de uma linha de investigação em economia regional. A exploração das propriedades do modelo, bem como a realização de estudos empíricos, tanto para a 
obtenção dos parâmetros da simulação quanto para a avaliação de seus resultados, constituem algumas das diretrizes para desenvolvimentos futuros.

A despeito das limitações apontadas, espera-se que o trabalho possa contribuir para o estabelecimento de uma ponte entre as proposições teóricas fundamentadas na não neutralidade da moeda e a problemática regional. A observação de desigualdades regionais persistentes é um indício de que muito ainda se encontra por fazer, de modo que a busca de soluções para os problemas em questão não pode prescindir de uma investigação aprofundada sobre a relação entre a moeda e o espaço.

\section{Referências bibliográficas}

BEARE, J. B. A monetarist model of regional business cycles. Journal of Regional Science, n. 16 , p. $57-63,1976$.

CARLINO, G. A.; DEFINA, R. Does monetary policy have differential regional effects? Business Review, p. 17-27, Mar. 1996.

. The differential regional effects of monetary policy: evidence from the

U. S. states. Philadelphia: Federal Reserve Bank, 1997. (Working Paper, n. 97-12).

DIXIT, A.; STIGLITZ, J. E. Monopolistic competition and optimal product diversity. American Economic Review, v. 67, p. 297-308, 1977.

DOW, S. C. (Ed.). Money and the economic process. Aldershot: Edward Elgar Publishing, 1993. $232 \mathrm{p}$.

EPSTEIN, J. M.; AXTELL, R. Growing artificial societies - social science from bottom-up. Washington: Brookings Institutions Press and the MIT Press, 1996. 209p.

FISHKIND, H. H. The regional impact of monetary policy: an economic simulation study of Indiana 1958-1973. Journal of Regional Science, n. 17, p. 77-88, 1977.

FOLEY, D. K. The strange story of the economic agent. New York: Department of Economics, Graduate Faculty - New School University, 2002. 14 p. Mimeografado.

FUJITA, M.; KRUGMAN, P.; VENABLES, A. The spatial economy. Cambridge: MIT, 1999. $391 \mathrm{p}$.

GARBAIX, X. Zipf's law for cities: an explanation. Quarterly Journal of Economics, v. 114, p. 739-767, 1999.

HOLLAND, J. H.; MILLER, J. H. Artificial adaptive agents in economic theory. AEA Papers and Proceedings, p. 365-370, May 1991.

ISARD, W. Location and space-economy: a general theory relating to industrial location market areas, land use, trade, and urban structure. Cambridge: The MIT Press, 1956. 350p.

KALDOR, N. The case for regional policies. Scottish Journal of Political Economy, v. 17, p. 337-48, 1970. 
KEYNES, J. M. A teoria geral do emprego, do juro e da moeda: inflação e deflação. São Paulo: Nova Cultural, 1985. 328p.

LIMA, G. T.; FREITAS, G. G. Debt financing and emergent dynamics of a financial fitness landscape. In: ENCONTRO NACIONAL DE ECONOMIA, 35, Recife: Anpec, 2007. Anais...

MENEZES, M.; CROCCO, M. Avaliação das condições de financiamento do desenvolvimento regional - notas preliminares. In: ENCONTRO NACIONAL DA ANPUR, 11, Salvador, 2005. Anais...

MINSKY, H. Stabilizing an unstable economy. New Haven: Yale University Press, 1986. $353 \mathrm{p}$.

MOORE, C. L.; HILL, J. M. Interregional arbitrage and the supply of loanable funds. Journal of Regional Science, v. 22, n. 4, p. 397-404, 1982.

MYRDAL, G. Teoria econômica e regiões subdesenvolvidas. Rio de Janeiro: ISEB, 1960. 210p.

PARUNAK, H.; SAVIT, R.; RIOLO, R. Agent-based modeling vs. equation-based modeling: a case stud and users' guide. Multi Agent Systems and Agent Based Simulation, v. 1534, p. 1-16, 1998.

PAULA, T. H. P. Financiamento e diversidade produtiva: Um modelo baseado em agentes com flutuações cíclicas emergentes. Revista de Economia Contemporânea, Rio de Janeiro, Instituto de Economia/UFRJ, v. 17, n. 1, p. 5-38, 2013.

RODRIGUEZ-FUENTES, C. J.; DOW, S. C. EMU and the regional impact of monetary policy. Regional Studies, v. 37, n. 9, p. 969-980, 2003.

ROSEN, K. T.; RESNICK, M. The size distribution of cities: an examination of the Pareto law and primacy. Journal of Urban Economics, v. 8, p. 165-186, 1980.

SILVERBERG, G. Evolutionary modeling in economics: recent history and immediate prospects. In: WORKSHOP ON EVOLUTIONARY ECONOMICS AS A SCIENTIFIC RESEARCH PROGRAMME, Stockholm, May, 1997. 16p.

; DOSI, G.; ORSENIGO, L. Innovation, diversity and diffusion: a self-organization model. The Economic Journal, v. 98, p. 1032-1054, 1988.

WILENSKY, U. NetLogo - Center for Connected Learning and Computer-Based Modeling. Evanston: Northwestern University, 1999.

WRAY, L. R. Minsky's financial instability hypothesis and the endogeneity of money. In: FAZZARI, Steven M.; PAPADIMITRIOU, Dimitri B. Financial conditions and macroeconomic performance: essays in honor of Hyman P. Minsky. Armonk: M. E. Sharpe, 1992. 195p. 